IMPLEMENTATION EVALUATION

\title{
Food Bank-Based Diabetes Prevention Intervention to Address Food Security, Dietary Intake, and Physical Activity in a Food-Insecure Cohort at High Risk for Diabetes
}

\author{
Kate Cheyne, $\mathrm{MPH}^{1}$; Morgan Smith, MS, RN, $\mathrm{CDE}^{2}$; Elizabeth M. Felter, DrPH, $\mathrm{MCHES}^{3}$; \\ Martha Orozco, BA ${ }^{1}$; Eric A. Steiner, MUP ${ }^{1}$; Yuae Park, MA ${ }^{3}$; Tiffany L. Gary-Webb, PhD, MHS ${ }^{3,4}$
}

\begin{abstract}
Accessible Version: www.cdc.gov/pcd/issues/2020/19_0210.htm
Suggested citation for this article: Cheyne K, Smith M, Felter EM, Orozco M, Steiner EA, Park Y, et al. Food Bank-Based Diabetes Prevention Intervention to Address Food Security, Dietary Intake, and Physical Activity in a Food-Insecure Cohort at High Risk for Diabetes. Prev Chronic Dis 2020;17:190210. DOI: https://doi.org/ 10.5888/pcd17.190210.
\end{abstract}

\section{PEER REVIEWED}

\section{Summary}

What is already known on this topic?

Food insecurity is a risk factor for type 2 diabetes, and household food insecurity is more prevalent where a household member has diabetes.

What is added by this report?

Food bank clients at risk for diabetes were offered a year-long diabetes prevention pilot intervention near Oakland, California. The intervention featured diabetes-appropriate food, text-based education, and health care referrals. At midpoint (6 months), we found significant improvements in food security, dietary intake, physical activity, and health status. Twelve-month results were unchanged from midpoint.

What are the implications for public health practice?

Food banks, which serve highly vulnerable communities, can improve food security and nutrition, but further reducing chronic disease risk and improving health outcomes may require additional partnerships.

\section{Abstract}

\section{Purpose and Objectives}

Although food insecurity is associated with poor dietary intake and risk of chronic disease, few studies have demonstrated the effectiveness of diabetes prevention interventions delivered through food banks. Food banks serve vulnerable communities. The pur- pose of this pilot project was to assess the effectiveness of a food bank-delivered intervention aimed at improving food security and reducing risk factors for type 2 diabetes among at-risk clients.

\section{Intervention Approach}

We screened adult English- and Spanish-speaking food bank clients for type 2 diabetes risk at 12 community food distribution sites in Alameda County, California. Screening and enrollment for a pilot intervention took place from November 2017 to March 2018. Intervention components were delivered from November 2017 through March 2019. The intervention included monthly diabetes-appropriate food packages, text-based health education, and referrals to health care.

\section{Evaluation Methods}

Food bank staff members administered surveys to participants at baseline, 6 months (midpoint), and 12 months (postintervention); participants self-reported all responses. Primary outcomes assessed were food security status, dietary intake, health-related behaviors, and body mass index (BMI). Information on demographic characteristics, food pantry access, health care use, and symptoms of depression was also collected.

\section{Results}

We screened 462 food bank clients for eligibility. Of the 299 who were eligible, 244 enrolled; $90.6 \%$ were female, $80.1 \%$ were Hispanic, and $49.1 \%$ had an annual household income less than $\$ 20,000$. At baseline, $68.8 \%$ of participants had low or very low food security. At midpoint, participants had significant improvements in food security status, dietary intake, physical activity, health status, and depression scores. Mean BMI did not change. 


\section{Implications for Public Health}

This intervention demonstrated that food banks can effectively screen clients at high risk for diabetes and improve household food security and other risk factors for diabetes. Food banks may be an important and strategic partner for health care systems or community-based organizations working to prevent diabetes in food-insecure populations.

\section{Introduction}

Food insecurity is a risk factor for type 2 diabetes $(1,2)$, and household food insecurity is more prevalent when a household member has diabetes (3). The US Department of Agriculture (USDA) defines food insecurity as a lack of consistent access to enough food for an active, healthy life (4). Compared with people in food-secure households, people in food-insecure households are more likely to report poorer health and symptoms of depression (5) and have a higher risk for diet-sensitive chronic conditions such as obesity, hypertension, and diabetes (6). Food-insecure patients with diabetes are also more likely than food-secure patients to have worse diabetes control (eg, hemoglobin $\mathrm{A}_{1 \mathrm{c}}$ levels), potentially increasing risk for diabetes-related complications $(7,8)$. Nationally, food insecurity affects more than 37.2 million people (9) and accounts for $\$ 77.5$ billion in additional annual health care costs in the United States (10).

Food banks serve a critical need in communities across the country. Feeding America, the nation's largest domestic hunger relief organization, collaborates with a network of 200 food banks and more than 60,000 affiliated food programs and pantries in the United States to provide food and services to more than 46 million people each year (11).

Food banks may be ideal partners or providers of disease prevention-focused programs for several reasons. First, food banks serve communities that have low socioeconomic status and a high risk for poor health. Nearly 3 of 4 client households in Feeding America's network are at or below $100 \%$ of the federal poverty level (11). Second, food-insecure households accessing a charitable food network may interact with a food bank more frequently than they interact with their health care providers, positioning food banks as venues for delivering health-related interventions to food-insecure populations at high risk for disease. Finally, food provision in vulnerable communities is the expertise of food banks. Food banks can provide nutritionally appropriate foods to food-insecure households that may otherwise struggle to maintain a diet suitable for disease prevention or management.

\section{Purpose and Objectives}

The purpose of this pilot project was to assess the effectiveness of a food bank-delivered intervention aimed at improving food security, dietary intake, and other risk factors for type 2 diabetes among food-insecure clients at risk for diabetes. We assessed the effect of diabetes-appropriate supplemental food and text-based education. Increased national interest in food insecurity among researchers, the public health community, and health care systems during the last decade (12) has produced a growing body of evidence (13-16) showing how food banks can effectively support health promotion and/or management of diet-sensitive chronic diseases such as diabetes. However, to our knowledge, no studies have examined the effectiveness of diabetes prevention strategies in a food bank setting.

\section{Intervention Approach}

Feeding America, in partnership with the University of Pittsburgh, developed the objectives, project framework, and evaluation plan for the pilot intervention. Intervention elements were based on previous food bank programs $(13,14)$ that leveraged food bank capacities and operational expertise to screen clients for disease risk and provide targeted nutrition services. Feeding America selected Alameda County Community Food Bank (ACCFB), in Oakland, California, as the intervention site through a competitive application process that considered 1) previous experience implementing formal research and evaluation protocols with fidelity, 2) capacity to support intervention components, and 3) leadership support. The project received approval from Copernicus Group Institutional Review Board. Screening and enrollment took place on a rolling basis, commencing in November 2017 and concluding in late March 2018. Intervention components were delivered from November 2017 through March 2019. We collected data at baseline, 6 months (midpoint), and 12 months (postintervention).

\section{Characteristics of intervention setting}

ACCFB, located in the heart of the Bay Area in California, serves an estimated 1 in 5 households in a linguistically and culturally diverse geography. ACCFB distributes roughly 35 million pounds of food each year through a network of more than 200 partner agencies and direct service programs. ACCFB was the first food bank in the nation to eliminate the distribution of soda and other sugary beverages in 2005. The food bank formalized a robust nutrition policy in 2012, and since 2014, the food bank has participated in 4 formal research studies. Roughly $60 \%$ to $65 \%$ of the volume that ACCFB distributes through its partner network is fresh (perishable, noncanned) fruits and vegetables.

\footnotetext{
The opinions expressed by authors contributing to this journal do not necessarily reflect the opinions of the U.S. Department of Health and Human Services, the Public Health Service, the Centers for Disease Control and Prevention, or the authors' affiliated institutions.
} 


\section{Intervention components}

Project intervention activities included monthly distribution of diabetes-appropriate food packages to participants; text-based health promotion education addressing physical activity and nutrition; text-based administrative and engagement messages; and referrals to health care and community-based diabetes prevention programs (DPPs).

Diabetes-appropriate food packages. Food packages were designed to increase access to and consumption of foods appropriate for diabetes prevention. Packages were created to approximately mirror USDA's MyPlate and Choose Healthy Options Program (17). These guidelines emphasize fresh produce, vegetables and fruits, whole grains, lean proteins, low-fat dairy, and healthy fats. Project packages contained shelf-stable products, including lean proteins, legumes, fruits and vegetables, and whole grains. Only canned products that were low in sodium and low in added sugars were included. Study participants received supplemental projectspecific food packages, in addition to having access to the food available through normal pantry distributions (ie, including fresh fruits and vegetables, proteins, and dairy).

Text-based health promotion education. By January 2018, all participants were enrolled in health promotion education programming delivered through CareMessage (www.caremessage.org) a nonprofit mobile health technology platform that designs mobile health tools for underserved patient populations. Participants first received a 24-week physical activity module, followed by a 24 week nutrition program. Each module delivered 3 to 5 text messages per week to participants to educate and nudge participants toward healthy behavior modifications. The text-based program was initiated for each participant by food bank staff members and was delivered in the participant's language of preference. By midpoint, participants had completed the physical activity program and were starting the nutrition module. Physical activity and nutrition education are core content areas of DPPs. Although the textbased health promotion programming was not a substitute for DPP classes, it did provide relevant and complementary health information to participants.

Text-based engagement and administrative messaging. All participants who provided consent for text messaging received general administrative messages during the project, with the goal to maintain or increase engagement in activities (primarily picking up project food packages). Messages included distribution reminders, date or time changes, and survey reminders. All messages were sent via the CareMessage platform, managed by food bank staff members, and delivered in the clients' language of preference.
Referrals to community-based DPPs. An initial goal of the project was to connect food bank clients to an existing community-based DPP for education and support aimed at lowering clients' diabetes risk. However, the DPP provider that the food bank had planned on working with underwent organizational changes and no longer had capacity to provide DPP classes during the project period. Food bank staff members were not able to find a replacement community-based DPP partner within the first 6 months of the study. Originally, the project was designed so that participants would be offered either a referral to a formal community-based DPP or the text-based health promotion education programming. In January 2018, we decided to enroll all participants who were interested in a community-based DPP into the text-based health promotion programs. When the project's enrollment closed in March 2018, we had initiated the text-based health program for 203 participants, including the 110 participants who initially expressed interest in the community-based DPP.

\section{Evaluation Methods}

The evaluation objectives for this pilot project were to assess changes in household food security, weekly minutes of physical activity, consumption of healthy foods (particularly fruits and vegetables), and weight/body mass index (BMI, measured as weight in kilograms divided by height in meters squared $\left.\left[\mathrm{kg} / \mathrm{m}^{2}\right]\right)$. Community-based DPPs that use the curricula available through the Centers for Disease Control and Prevention (CDC) expect the main outcomes to be demonstrated within the first 6 months of the program and maintained in months 6 through 12. In conceptualizing this study, we had originally planned to align the 12 months of supplemental food packages with the duration of a communitybased DPP, but we were unable to offer the DPP in the first 6 months. The text-based program we offered is not recognized as a replacement for DPP; DPP's strength is an intensive peer-learning model that requires active engagement and interaction between participants during the year-long program. For this pilot project, we expected improvements in food security, dietary quality, and physical activity to improve within the first 6 months of the program and that improvements would be maintained in months 6 through 12. We did not expect to see improvement in weight or BMI once we were unable to offer referral to a community-based DPP. We felt these expectations were consistent with the logic of the national DPP and with other research done in conjunction with food banks.

\section{Data sources}

The primary data collection tools for the project were surveys completed at baseline, midpoint, and postintervention, at which point participants exited the program. All survey data, including weight and height, from which we computed BMI values, were

The opinions expressed by authors contributing to this journal do not necessarily reflect the opinions of the U.S. Department of Health and Human Services, the Public Health Service, the Centers for Disease Control and Prevention, or the authors' affiliated institutions. 
self-reported. Participant data were collected by using electronic tablets and a centralized data collection platform (Qualtrics), which was managed by research team members at the University of Pittsburgh. Survey versions were available in English and Spanish and were administered in person by food bank staff members. Food bank staff members timed the midpoint and postintervention surveys by measuring 6 months and 12 months, within a 6-week window, from the participant's enrollment date. Participants were not required to complete surveys to receive the intervention. Participants received a $\$ 10$ gift card upon completion of each of the baseline, midpoint, and postintervention surveys as compensation for their time.

\section{Measures}

We used a screening survey to assess diabetes risk and project eligibility and collect data on demographic characteristics. The screening survey included CDC's 7-item Prediabetes Risk Test (https://www.cdc.gov/prediabetes/takethetest). The baseline, midpoint, and postintervention surveys consisted of questions on food security, dietary intake, use of a food pantry, participation in the Supplemental Nutrition Assistance Program (SNAP), general health, height (at baseline only) and weight, and satisfaction with the project (midpoint and postintervention only). Because a high BMI is a metric used to determine DPP eligibility and weight loss is a goal in the DPP, we collected self-reported data on height and weight. Previous studies demonstrated the ability to assess significant changes in food security and dietary intake during a 6month nutrition intervention $(13,14)$. As previously stated, we prioritized changes in food security and dietary intake at 6 months and evaluated for maintenance and changes again at 12 months once we were no longer able to provide a DPP referral.

We used the USDA Economic Research Service's 6-item screener (18) to assess food security status of participant households at baseline, midpoint, and postintervention. A food security score, scaled from 0 to 6 , was calculated by summing individual affirmative answers to the 6-item assessment. The higher the score, the greater the food insecurity. Food security status was categorized according to USDA guidelines as very low (5 or 6); low (2-4); and high or marginal (0 or 1). We adapted questions on dietary intake, SNAP participation, and other measures from the FRESH Foods Survey (19) and questions on health status and number of physical activity minutes per week from CDC's Behavioral Risk Factor Surveillance System (20). We calculated BMI by using participant-reported data on height and weight.

We used the 2-item Patient Health Questionnaire-2 (PHQ-2) to assess symptoms of depression among participants. This questionnaire asks about the frequency of depressed mood in the previous
2 weeks, with a score ranging from 0 to 6 ; if the score is 3 or greater, a major depressive condition is likely (21).

We also measured participant engagement in the project. We established 2 categories of engagement: a participant receiving at least $70 \%$ of program food packages was categorized as highly engaged, and a participant receiving less than $70 \%$ was categorized as less engaged.

\section{Participant recruitment}

During project development, we determined a target number of participants $(\mathrm{N}=250)$ by considering operational and programming criteria and reviewing recently conducted programs $(13,14)$ that had similar aims and objectives rather than by considering statistical criteria (ie, ascertaining a sample size appropriate for statistical purposes).

We recruited participants from 12 food pantries affiliated with the food bank through flyers, posters, in-person announcements, and word-of-mouth. Screening and enrollment began in November 2017 and concluded in late March 2018. To identify eligible participants, food bank staff members and volunteers administered a screening questionnaire to adult food pantry clients as they waited in line at food distribution sites. Screening questions assessed eligibility (language, age, diabetes history) and included demographic questions (eg, sex, household income, race, ethnicity). Inclusion criteria were a clinical history of prediabetes (by self-report) or a high score $(\geq 9)$ on CDC's Prediabetes Risk Test, existing or new food pantry client, aged 18 or older, and English or Spanish verbal fluency. Exclusion criteria were the following: any previous diagnosis of diabetes (not gestational diabetes), pregnancy, fewer than 6 weeks postpartum, or cognitive impairment. Eligible clients who met inclusion criteria and were interested in participating were considered to be enrolled after providing informed consent and contact information and selecting project activities of interest.

At enrollment and during follow-up assessments, participants were asked about their access to primary health care providers. Participants who stated they did not have a primary care provider were given information about local community health care organizations and encouraged by project staff members to establish contact with a health care clinic.

\section{Statistical analyses}

All participant surveys were completed from November 2017 through May 2019. Research team members from the University of Pittsburgh conducted descriptive (univariate and bivariate) analyses to assess significant changes in participant metrics between enrollment and midpoint and between enrollment and 12 months.

\footnotetext{
The opinions expressed by authors contributing to this journal do not necessarily reflect the opinions of the U.S. Department of Health and Human Services, the Public Health Service, the Centers for Disease Control and Prevention, or the authors' affiliated institutions.
} 
We used $\chi^{2}$ analyses to describe differences in categorical variables and Fisher exact tests when cell sizes were small $(<5$ participants). We used $t$ tests to describe differences in continuous variables. We considered results to be significant at $P \leq .05$. All statistical analyses were performed by using Stata version 14 (StataCorp LLC).

\section{Results}

Food bank staff members screened 462 food pantry clients aged 18 or older at 12 sites beginning in November 2017. Of the 422 clients who completed CDC's Prediabetes Risk Test, 244 (57.8\%) were eligible, consented to participate, and completed the baseline survey. Of the 422 clients, we excluded 163 for the following reasons: 123 clients had a score less than 9 on CDC's Prediabetes Risk Test, 32 clients had a previous diagnosis of diabetes, 6 clients discontinued the screening process, and 2 clients were pregnant or fewer than 6 weeks postpartum (Figure). A total of 244 participants consented to receive project food packages and administrative text messages throughout the year-long project. Additionally, $83.2 \%(n=203)$ were interested in the text-based education at baseline, and $45.1 \%(n=110)$ were interested in a referral to a community-based DPP provider.

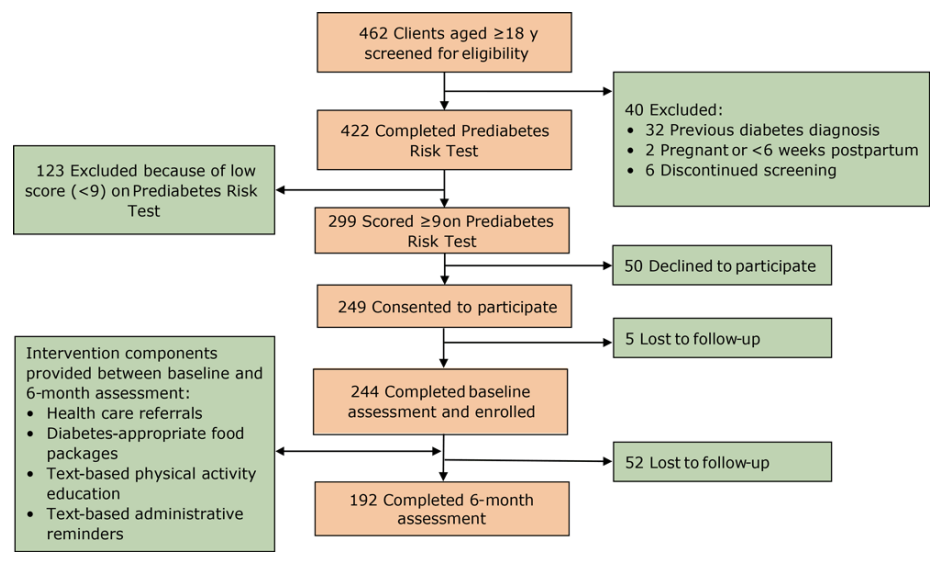

Figure. Pilot project enrollment and implementation from baseline to 6 months, food bank-based diabetes prevention intervention, Alameda, California, 2017-2019. The Prediabetes Risk Test is available from the Centers for Disease Control and Prevention at https://www.cdc.gov/prediabetes/takethetest.

\section{Baseline characteristics of participants}

Of 192 participants who completed both the baseline survey and midpoint survey, $174(90.6 \%)$ were female. Of the 186 participants who answered the question on race/ethnicity, $149(80.1 \%)$ were Hispanic or Latino; 14 (7.5\%) were black or African American, and $13(7.0 \%)$ were Asian (Table 1). Using self-reported height and weight at baseline, we found that $95.9 \%$ of participants were overweight (BMI 25.0-29.9 kg/m²) or obese (BMI >30 kg/ $\mathrm{m}^{2}$ ). Nearly half (49.1\%) of participants reported a household income less than $\$ 20,000$, and $59.9 \%$ reported renting as their living situation.

At baseline, 65.8\% (125 of 190) of respondents indicated that "worrying food would run out" was "sometimes true" or "often true"; $71.7 \%$ (137 of 191) of respondents indicated that not being able to afford balanced meals was "sometimes true" or "often true"; $43.6 \%$ (82 of 188) of respondents indicated that household adults skip meals; $28.9 \%$ (13 of 45 ) of respondents reported household adults skip meals almost every month; 68.8\% (132 of 192) of respondents had low or very low food security status; and $30.2 \%$ (58 of 192) of respondents were participating in SNAP.

In addition, 84.8\% (162 of 191) of respondents reported having a place to go when they are sick and need advice about their health, and $92.1 \%$ (176 of 191) of respondents reported having health insurance coverage. Most (79.4\%) participants reported last visiting a physician within the past 6 months for a routine checkup. In our study population, $92.1 \%$ (176 of 191) of respondents reported having health insurance coverage: of the 106 who answered about type of coverage, $38.7 \%(\mathrm{n}=41)$ reported coverage through Medicaid, 23.6\% $(\mathrm{n}=25)$ indicated private insurance, and $23.6 \%(\mathrm{n}=$ 25) reported benefits through Alameda County's HealthPAC program, which offers health care services to low-income residents not otherwise covered by private insurance or Medicaid. Despite good health care coverage in this population, 19.9\% (38 of 191) of respondents reported that they found it difficult to see a physician because of cost.

\section{Midpoint changes}

At midpoint, 192 of 244 participants (78.7\%) completed surveys administered by food bank staff members; 52 were lost to followup. We found significant improvements in food security status, dietary intake, physical activity, and depression scores. We found no significant changes in weight or BMI.

Food security status. The percentage of participants reporting that household adults skip meals decreased from $43.6 \%$ at baseline to $29.3 \%$ (Pearson $\chi^{2}=98.6, P<.001$ ) at midpoint (Table 2 ). The percentage of participants with low or very low food security status decreased from $68.8 \%$ at baseline to $62.5 \%$ at midpoint (Pearson $\left.\chi^{2}=72.6, P<.001\right)$.

Physical activity and general health. The minutes of physical activity per week reported increased from 95.6 to 145.1 (paired $t$ test $=4.05, P<.001)$ among participants, and the percentage of

The opinions expressed by authors contributing to this journal do not necessarily reflect the opinions of the U.S. Department of Health and Human Services, the Public Health Service, the Centers for Disease Control and Prevention, or the authors' affiliated institutions. 
participants who reported regular physical activity at least once per week increased from $62.5 \%$ to $80.7 \%$ (Pearson $\chi^{2}=21.0, P<$ $.001)$ (Table 3). The percentage of participants who reported their health status as poor or fair declined from $73.9 \%$ to $60.1 \%$ (Fisher exact $=39.19, P<.001)$.

Dietary intake. Consumption of the following healthy foods increased significantly: green salad, nonfried vegetables, cooked beans, cooked whole grains, whole-grain foods, and fruits and vegetables (Table 4). Consumption of the following unhealthy foods decreased significantly: any sweetened drinks, fried potatoes, candy/chocolate, and cookies/cakes and other sugary dessert foods.

Engagement. Half of participants were categorized as highly engaged and half were less engaged. Regardless of how many packages a participant picked up, food security and fruit and vegetable consumption improved significantly and in similar magnitudes. Highly engaged participants were more food secure than the less engaged group at baseline (Table 5). Although food security improved significantly in both groups, the food security scores of the less engaged group at midpoint were lower than the food security scores of the highly engaged group at baseline.

Consumption of fruits and vegetables between baseline and midpoint improved significantly in both groups. The 2 groups also had similar consumption patterns at baseline and at midpoint. The consumption of whole grains improved significantly in the highly engaged group. We found a similar improvement in the less engaged group, but it was not significant.

\section{Preliminary analyses at postintervention}

At postintervention, 159 of $244(65.2 \%)$ participants completed surveys administered by food bank staff members; 33 participants were lost to follow-up between midpoint and postintervention. We conducted preliminary analyses comparing baseline and postintervention outcomes. Results indicated improved food security, dietary intake, physical activity, health status, and depression scores $(P<.001$ for each). Although results at postintervention remained significantly different from baseline, they were generally unchanged from the results observed at midpoint, indicating maintenance of improvements observed at the 6-month mark.

\section{Implications for Public Health Practice}

The purpose of this pilot project was to assess the effectiveness of a food bank-delivered intervention aimed at improving food security and reducing risk factors for type 2 diabetes among at-risk clients. The screening and enrollment process showed that 7 in 10 clients were at high risk for diabetes. In the participant group, $95.8 \%$ were overweight or obese, $43.6 \%$ reported adults skipping meals in the household, and nearly 3 in 4 (73.9\%) characterized their general health as fair or poor. After a 6-month intervention composed mainly of supplemental diabetes-appropriate food and text-based health education, scores for food security, dietary intake, physical activity, health status, and depression improved significantly. When stratified by engagement level, our results aligned with the results of other studies finding lower levels of participation among people with lower levels of food security (22). This finding may indicate that people with very low food security may have additional barriers that impede engagement. Gains in food security, dietary intake, physical activity, health status, and depression scores demonstrated at postintervention were unchanged from those at midpoint.

BMI did not change significantly from baseline to midpoint or postintervention, but we did not anticipate improvement in BMI because we were not able to offer referrals to a community-based DPP. Improvements in food security and dietary intake outcomes are consistent with improvements found in other food bank-based interventions that focused on diabetes management rather than diabetes prevention $(12,13)$. The retention rate for our project was nearly $80 \%$ at midpoint, suggesting that the program was accessible and relevant to a population that faced numerous challenges to program participation (eg, transportation, childcare, work) during the year-long intervention.

In our study population, $92.1 \%$ reported having health insurance coverage, which is consistent with the countywide average for health insurance coverage since implementation of the Affordable Care Act (23).

Although we did not explicitly explore the effect of the intervention on dietary intake among nonparticipating household members, participants informally commented to food bank staff members that the intervention benefitted the entire household, including children and other adult household members who may have been struggling to manage diagnosed type 2 diabetes. The rate of participation among women in this project was high. It mirrors the representation of women at the food bank's distributions generally and rates among women observed in other food bank-based research projects $(13,14)$. Mothers and women often act as nutritional gatekeepers for the household; women are and should be an important group to target for similar programs.

The rate of participation in SNAP among project participants was lower than expected, and it remained relatively unchanged during the intervention. Some households lost their SNAP benefits during the first 6 months of the intervention, while other households gained access to SNAP during this time. Although food bank staff members regularly conduct outreach activities at many distribu-

\footnotetext{
The opinions expressed by authors contributing to this journal do not necessarily reflect the opinions of the U.S. Department of Health and Human Services, the Public Health Service, the Centers for Disease Control and Prevention, or the authors' affiliated institutions.
} 
tion sites, not every distribution site for this project had an outreach staff member in attendance to encourage and facilitate SNAP enrollment and maintenance.

This pilot project demonstrated that food banks serve vulnerable populations at high risk for poor health and chronic disease, and that delivery of disease prevention programs through food banks can be effective, accessible, and relevant for populations that may not be able to access similar services through traditional health care systems or community-based programs. Participants in this pilot project had significant improvements in health-related metrics despite not having access to a formal DPP. More work is needed, however, to build DPP infrastructure and the systems necessary to link DPPs to health care providers and community organizations like food banks to ensure high-risk populations can access comprehensive prevention services.

This project had several limitations. The project was offered only in English and Spanish, which limited our ability to screen and enroll all clients at high risk of diabetes. We recruited a convenience sample, and recruitment was driven by the agencies and locations willing to work with food bank staff members. The study was conducted in cooperation with a single food bank in an urban environment and lacked a comparison group, and results may not be generalizable to other populations and communities in the United States. This program was available to participants for only 12 months. Considering the structural challenges and barriers that food pantry clients may face in accessing and maintaining a diet appropriate for diabetes prevention, 12 months may not be sufficient to achieve weight-related outcomes or understand long-term effects. Relatedly, temporal bias may have affected the accuracy of self-reported baseline and follow-up measures.

Social desirability bias may have influenced self-reported risk factors at baseline and outcomes at follow-up. Baseline demographic information aligns with information in previous Hunger in America studies that describe the populations served by food banks. Nearly half of participants in this pilot program were living on less than $\$ 20,000$ in annual household income. The 2014 Hunger in America study (11) showed that half of ACCFB's clients get all or most of their food from the food bank.

Lastly, the food bank was not able to implement all intervention components as originally planned. The inability to offer a referral to a community-based DPP may have affected participant engagement and outcomes for those who would have preferred an in-person option. The text-based health education component was also somewhat delayed for this group, which originally requested referrals to community-based DPPs. We made the decision to enroll all participants in the text-based program in January 2018. For some participants, this enrollment was 2 months after they had enrolled in the overall program and began receiving supplemental food packages. Despite this limitation, we did not observe lower rates of program engagement for this group.

Food bank clients are interested in receiving healthy (or healthier) foods from their pantry or food bank (24). Increasingly, many food banks no longer see themselves solely as antihunger organizations but as partners to clients and communities in helping reduce the health concerns that disproportionately affect the communities they serve (25). One in 3 adults nationally are estimated to have prediabetes, and $90 \%$ of these adults do not know they have prediabetes (26). In a 2016 study, $46 \%$ of all adults in California were estimated to have prediabetes or undiagnosed diabetes (27). With diabetes diagnoses come higher out-of-pocket medical costs (28), and these costs add to the challenges among food-insecure populations in accessing a diabetes-appropriate diet. In this project, we found that 70.9\% (299 of 422) of clients screened had prediabetes, according to CDC's Prediabetes Risk Test, highlighting the opportunity to engage food banks as partners or foci for interventions in populations at high risk of diabetes. More research is needed to identify how and if including a DPP as part of a food bank intervention supports clients in meeting weight-loss goals that are part of diabetes prevention strategies. However, it is imperative that public health and health care systems develop the infrastructure for broad dissemination of evidenced-based programs like the DPP and ensure it is accessible to and tailored for those communities at the highest risk of diabetes.

To achieve the "triple aim" in health care (improved population health, improved patient experience, and reduced health care costs) (29), health care organizations are increasingly working to address social determinants of health — such as food insecurity with community partners outside traditional health care settings. This work has contributed to an increasing national interest in exploring food banks and food pantries as settings through which health care interventions in general, and diabetes prevention interventions in particular, can be conducted. Further exploration and evaluation of similar models should be pursued, particularly because these models often reach marginalized populations who are at the highest risk for poor health and who face multiple barriers to accessing and using health care services that target disease prevention and health promotion.

\section{Acknowledgments}

This program was supported in part by a grant received from Feeding America and the Cargill Corporation. General food bank funds were also used to support program activities. The authors acknowledge and thank the program participants as well as the nu-

The opinions expressed by authors contributing to this journal do not necessarily reflect the opinions of the U.S. Department of Health and Human Services, the Public Health Service, the Centers for Disease Control and Prevention, or the authors' affiliated institutions. 
merous food bank staff members and volunteers who contributed to program activities. The content of this article is solely the responsibility of the authors and does not necessarily represent the official views of the Alameda County Community Food Bank, the University of Pittsburgh Graduate School of Public Health, or Feeding America. No copyrighted materials were used in the preparation of this article.

\section{Author Information}

Corresponding Author: Kate Cheyne, MPH, Associate Director of Research, Alameda County Community Food Bank, 7900 Edgewater Dr, Oakland, CA 94621. Telephone: 510-635-3663. Email: kcheyne@accfb.org.

Author Affiliations: ${ }^{1}$ Alameda County Community Food Bank, Oakland, California. ${ }^{2}$ Feeding America, Chicago, Illinois. ${ }^{3}$ Department of Behavioral and Community Health Sciences, University of Pittsburgh Graduate School of Public Health, Pittsburgh, Pennsylvania. ${ }^{4}$ Department of Epidemiology, University of Pittsburgh Graduate School of Public Health, Pittsburgh, Pennsylvania.

\section{References}

1. Seligman HK, Bindman AB, Vittinghoff E, Kanaya AM, Kushel MB. Food insecurity is associated with diabetes mellitus: results from the National Health Examination and Nutrition Examination Survey (NHANES) 1999-2002. J Gen Intern Med 2007;22(7):1018-23.

2. Tait CA, L'Abbé MR, Smith PM, Rosella LC. The association between food insecurity and incident type 2 diabetes in Canada: a population-based cohort study. PLoS One 2018; 13(5):e0195962.

3. Gucciardi E, Vahabi M, Norris N, Del Monte JP, Farnum C. The intersection between food insecurity and diabetes: a review. Curr Nutr Rep 2014;3(4):324-32.

4. US Department of Agriculture Economic Research Service. Definitions of food security. https:/www.ers.usda.gov/topics/ food-nutrition-assistance/food-security-in-the-us/definitionsof-food-security/\#ranges. Updated September 5, 2018. Accessed June 1, 2019.

5. Vozoris NT, Tarasuk VS. Household food insufficiency is associated with poorer health. J Nutr 2003;133(1):120-6.

6. Seligman HK, Laraia BA, Kushel MB. Food insecurity is associated with chronic disease among low-income NHANES participants. [Published correction appears in J Nutr 2011; 141(3):542.] J Nutr 2010;140(2):304-10.
7. Seligman HK, Jacobs EA, López A, Tschann J, Fernandez A. Food insecurity and glycemic control among low-income patients with type 2 diabetes. Diabetes Care 2012;35(2):233-8.

8. Berkowitz SA, Baggett TP, Wexler DJ, Huskey KW, Wee CC. Food insecurity and metabolic control among U.S. adults with diabetes. Diabetes Care 2013;36(10):3093-9.

9. Coleman-Jensen A, Rabbitt MP, Gregory CA, Singh A. Household food security in the United States in 2018. Economic Research Report Number 270. Washington (DC): US Department of Agriculture Economic Research Service; 2019.

10. Berkowitz SA, Basu S, Meigs JB, Seligman HK. Food insecurity and health care expenditures in the United States, 2011-2013. Health Serv Res 2018;53(3):1600-20.

11. Weinfield N, Mills G, Borger C, Gearing M, Macaluso T, Montaquila J, et al.Hunger in America 2014. Chicago (IL): Feeding America; 2014. https:/www.feedingamerica.org/ research/hunger-in-america?s_src=W196ORGSC. Accessed November 5, 2019.

12. Seligman HK, Berkowitz SA. Aligning programs and policies to support food security and public health goals in the United States. Annu Rev Public Health 2019;40(1):319-37.

13. Seligman HK, Smith M, Rosenmoss S, Marshall MB, Waxman E. Comprehensive diabetes self-management support from food banks: a randomized controlled trial. Am J Public Health 2018;108(9):1227-34.

14. Seligman HK, Lyles C, Marshall MB, Prendergast K, Smith $\mathrm{MC}$, Headings A, et al. A pilot food bank intervention featuring diabetes-appropriate food improved glycemic control among clients in three states. Health Aff (Millwood) 2015; 34(11):1956-63.

15. Feeding America. Our research: hunger and health. https:// www.feedingamerica.org/research/hunger-and-health-research. Accessed June 11, 2019.

16. An R, Wang J, Liu J, Shen J, Loehmer E, McCaffrey J. A systematic review of food pantry-based interventions in the USA. Public Health Nutr 2019;22(9):1704-16.

17. MAZON. A Jewish Response to Hunger. Choose Healthy Options Program (CHOP): implementation guide. 2012. MAZON and Greater Pittsburgh Community Food Bank. https://mazon.org/assets/Uploads/HOHM-CHOPGuide.pdf. Accessed June 1, 2019.

18. US Department of Agriculture Economic Research Service. Six-item short form of the Food Security Survey Module. https://www.ers.usda.gov/topics/food-nutrition-assistance/ food-security-in-the-us/survey-tools/\#six. Accessed June 1, 2019.

\footnotetext{
The opinions expressed by authors contributing to this journal do not necessarily reflect the opinions of the U.S. Department of Health and Human Services, the Public Health Service, the Centers for Disease Control and Prevention, or the authors' affiliated institutions.
} 
19. Calloway EE, Seligman HK, Boyd LW, Stern KL, Rosenmoss S, Yaroch AL. Development and testing of the FRESH Foods Survey to assess food pantry clients' dietary behaviours and correlates. Public Health Nutr 2019;22(12):2170-8.

20. Centers for Disease Control and Prevention. Behavioral Risk Factor Surveillance System Survey questionnaire. Atlanta (GA): US Department of Health and Human Services, Centers for Disease Control and Prevention; 2015.

21. Kroenke K, Spitzer RL, Williams JB. The Patient Health Questionnaire-2: validity of a two-item depression screener. Med Care 2003;41(11):1284-92.

22. Kirkpatrick SI, Tarasuk V. Food insecurity and participation in community food programs among low-income Toronto families. Can J Public Health 2009;100(2):135-9.

23. US Census Bureau. Small area health insurance estimates: 2017. https://www.census.gov/content/dam/Census/library/ publications/2019/demo/p30-05.pdf. Accessed November 5, 2019.

24. Bomberg EM, Neuhaus J, Hake MM, Engelhard EM, Seligman HK. Food preferences and coping strategies among diabetic and nondiabetic households served by US food pantries. J Hunger Environ Nutr 2019;14(1-2):4-17.

25. Wetherill MS, White KC, Seligman HK. Nutrition-focused food banking in the United States: a qualitative study of healthy food distribution initiatives. J Acad Nutr Diet 2019; 119(10):1653-65.

26. Centers for Disease Control and Prevention. National diabetes statistics report, 2017. Atlanta (GA): Centers for Disease Control and Prevention, US Department of Health and Human Services; 2017.

27. Babey SH, Wolstein J, Diamant AL, Goldstein H. Prediabetes in California: nearly half of California adults on path to diabetes. Los Angeles (CA): UCLA Center for Health Policy Research and California Center for Public Health Advocacy; 2016.

28. Berkowitz SA, Seligman HK, Choudhry NK. Treat or eat: food insecurity, cost-related medication underuse, and unmet needs. Am J Med 2014;127(4):303-310.e3.

29. Institute for Healthcare Improvement. Triple aim - concept design. Institute for Healthcare Improvement. http:// www.ihi.org/Engage/Initiatives/TripleAim/Documents/ ConceptDesign.pdf. Accessed June 1, 2019.

\footnotetext{
The opinions expressed by authors contributing to this journal do not necessarily reflect the opinions of the U.S. Department of Health and Human Services, the Public Health Service, the Centers for Disease Control and Prevention, or the authors' affiliated institutions.
} 


\section{Tables}

Table 1. Baseline Sociodemographic Characteristics of Participants $(N=192)$ in a Food Bank-Based Diabetes Prevention Intervention in Alameda County, California, 2017-2019a

\begin{tabular}{|c|c|c|}
\hline Characteristic & No. of Respondents & Value \\
\hline Age, mean (SD), y & 192 & $48.5(12.7)$ \\
\hline Female sex & 192 & $174(90.6)$ \\
\hline \multicolumn{3}{|l|}{ Race/ethnicity } \\
\hline Asian & \multirow[t]{4}{*}{186} & $13(7.0)$ \\
\hline Black or African American & & $14(7.5)$ \\
\hline Hispanic or Latino & & $149(80.1)$ \\
\hline Other & & $10(5.4)$ \\
\hline \multicolumn{3}{|l|}{ Body mass index } \\
\hline Normal or healthy (18.5-24.9) & \multirow[t]{3}{*}{192} & $8(4.2)$ \\
\hline Overweight (25.0-29.9) & & $66(34.4)$ \\
\hline Obese $(\geq 30.0)$ & & $118(61.5)$ \\
\hline \multicolumn{3}{|l|}{ Annual household income, \$ } \\
\hline$<20,000$ & \multirow[t]{4}{*}{169} & $83(49.1)$ \\
\hline $20,000-39,999$ & & 64 (37.9) \\
\hline $40,000-59,999$ & & $17(10.1)$ \\
\hline $60,000-79,999$ & & $5(3.0)$ \\
\hline \multicolumn{3}{|l|}{ Education } \\
\hline$<$ High school or GED & \multirow[t]{5}{*}{192} & $108(56.3)$ \\
\hline Completed high school or GED & & $40(20.8)$ \\
\hline Some college, but no degree & & $13(6.8)$ \\
\hline Completed 2-year degree & & $13(6.8)$ \\
\hline Completed 4-year degree or higher & & $18(9.4)$ \\
\hline \multicolumn{3}{|l|}{ Employment status } \\
\hline Not employed & \multirow[t]{5}{*}{192} & $48(25.0)$ \\
\hline Retired, disabled, homemaker/stay-at-home parent, or student & & $72(37.5)$ \\
\hline Employed in temporary or part-time job & & $37(19.3)$ \\
\hline Employed full time & & $28(14.6)$ \\
\hline Other & & $7(3.6)$ \\
\hline \multicolumn{3}{|l|}{ Home ownership } \\
\hline Rent & \multirow[t]{3}{*}{192} & $115(59.9)$ \\
\hline Own & & $33(17.2)$ \\
\hline Other & & $44(22.9)$ \\
\hline \multicolumn{3}{|l|}{ SNAP benefits } \\
\hline
\end{tabular}

Abbreviation: SNAP, Supplemental Nutrition Assistance Program.

${ }^{a}$ All values are number (percentage) unless otherwise noted. Food bank staff members administered surveys to food pantry clients aged $\geq 18$ at 12 sites. Includes only participants who completed both the baseline survey and the midpoint survey and had no missing values. Numbers may not add to 192 because not all participants answered all questions. Percentages are based on the number of participants who answered question; percentages may not sum to 100 because of rounding.

${ }^{b}$ Calculated as weight in kilograms divided by height in meters squared $\left(\mathrm{kg} / \mathrm{m}^{2}\right)$ using self-reported height and weight at baseline.

(continued on next page)

The opinions expressed by authors contributing to this journal do not necessarily reflect the opinions of the U.S. Department of Health and Human Services, the Public Health Service, the Centers for Disease Control and Prevention, or the authors' affiliated institutions. 
(continued)

Table 1. Baseline Sociodemographic Characteristics of Participants $(N=192)$ in a Food Bank-Based Diabetes Prevention Intervention in Alameda County, California, 2017-2019 a

\begin{tabular}{|c|c|c|}
\hline Characteristic & No. of Respondents & Value \\
\hline No. of households receiving SNAP at baseline & 192 & $58(30.2)$ \\
\hline No. of households receiving SNAP at 6 months & 192 & $44(22.9)$ \\
\hline No. of households not receiving SNAP at baseline, but receiving it at 6 months & 192 & $12(6.3)$ \\
\hline
\end{tabular}

Abbreviation: SNAP, Supplemental Nutrition Assistance Program.

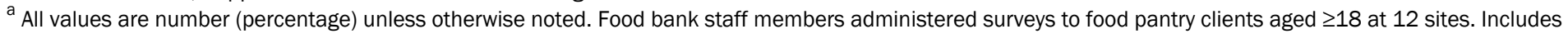

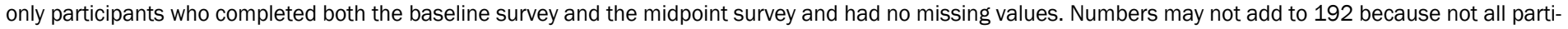

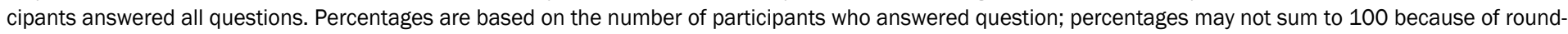
ing.

${ }^{\mathrm{b}}$ Calculated as weight in kilograms divided by height in meters squared $\left(\mathrm{kg} / \mathrm{m}^{2}\right)$ using self-reported height and weight at baseline. 
Table 2. Changes in Food Security at 6-Month Assessment Among Participants $(\mathrm{N}=192)$ in a Food Bank-Based Diabetes Prevention Intervention in Alameda County, California, 2017-2019

\begin{tabular}{|c|c|c|c|c|}
\hline Characteristic & No. of Respondents & Baseline, №. (\%) & 6-Month Assessment, No. (\%) & $P$ Value $^{\mathrm{b}}$ \\
\hline \multicolumn{5}{|c|}{ Food Security } \\
\hline \multicolumn{5}{|l|}{ Worried food will run out } \\
\hline Never true & \multirow[t]{3}{*}{190} & $65(34.2)$ & $70(36.8)$ & \multirow[t]{3}{*}{$<.001$} \\
\hline Sometimes true & & $98(51.6)$ & $102(53.7)$ & \\
\hline Often true & & $27(14.2)$ & $18(9.5)$ & \\
\hline \multicolumn{5}{|l|}{ Cannot afford balanced meals } \\
\hline Never true & \multirow[t]{3}{*}{191} & $54(28.3)$ & $59(30.9)$ & \multirow[t]{3}{*}{$<.001$} \\
\hline Sometimes true & & $100(52.4)$ & $110(57.6)$ & \\
\hline Often true & & $37(19.4)$ & $22(11.5)$ & \\
\hline Adults skip meals & 188 & $82(43.6)$ & $55(29.3)$ & $<.001$ \\
\hline \multicolumn{5}{|c|}{ Frequency with which adults skip meals, among those who reported skipping meals } \\
\hline Only 1 or 2 months & \multirow[t]{3}{*}{45} & $8(17.8)$ & $6(13.3)$ & \multirow[t]{3}{*}{.44} \\
\hline Some months but not every month & & $24(53.3)$ & $28(62.2)$ & \\
\hline Almost every month & & $13(28.9)$ & $11(24.4)$ & \\
\hline Eat less than should & 187 & $84(44.9)$ & $55(29.4)$ & $<.001$ \\
\hline Hungry but didn't eat & 190 & $40(21.1)$ & $33(17.4)$ & $<.001$ \\
\hline Food security score, mean (median [IQR]) ${ }^{\mathrm{c}, \mathrm{d}}$ & 192 & $2.8(2.0[1.0-5.0])$ & $2.3(2.0[1.0-4.0])$ & $<.001$ \\
\hline \multicolumn{5}{|l|}{ Food security status $^{c}$} \\
\hline High or marginal food security & \multirow[t]{3}{*}{192} & $60(31.3)$ & $72(37.5)$ & $<.001$ \\
\hline Low food security & & $80(41.7)$ & $87(45.3)$ & \\
\hline Very low food security & & $52(27.1)$ & $33(17.2)$ & \\
\hline \multicolumn{5}{|c|}{ Use of Project Food Packages } \\
\hline \multicolumn{5}{|c|}{ How much of supplemental food did the participant and household eat? } \\
\hline Little & \multirow[t]{4}{*}{191} & NA & $3(1.6)$ & \multirow[t]{4}{*}{ NA } \\
\hline Some & & NA & $26(13.6)$ & \\
\hline Most & & NA & $72(37.7)$ & \\
\hline All & & NA & $90(47.1)$ & \\
\hline \multicolumn{5}{|c|}{ How much of supplemental food was thrown out or given away? } \\
\hline None & \multirow[t]{4}{*}{192} & NA & $134(69.8)$ & \multirow[t]{4}{*}{ NA } \\
\hline Little & & NA & $38(19.8)$ & \\
\hline Some & & NA & $18(9.4)$ & \\
\hline Most & & NA & $2(1.0)$ & \\
\hline
\end{tabular}

Abbreviation: IQR, interquartile range; NA, not applicable.

${ }^{a}$ All values are number (percentage) unless otherwise noted. Food bank staff members administered surveys to food pantry clients aged $\geq 18$ at 12 sites. Includes only participants who completed both the baseline survey and the midpoint survey.

${ }^{b} P$ value determined by Pearson $x^{2}$ test for categorical indicators and paired $t$ test for continuous indicators.

' USDA Economic Research Service's 6-item screener (18) was used to assess food security score and food security status of participant households. The score was determined by summing individual affirmative answers to the 6-item assessment. Score is scaled from 0 to 6 , with higher scores indicating low or very low food security. Food security status was categorized as very low (5 or 6); low (2-4); and high or marginal (0 or 1$)$.

${ }^{d}$ The difference in mean food security score between baseline and 6-month assessment was -0.5 (SD, 1.5).

(continued on next page)

The opinions expressed by authors contributing to this journal do not necessarily reflect the opinions of the U.S. Department of Health and Human Services, the Public Health Service, the Centers for Disease Control and Prevention, or the authors' affiliated institutions. 


\section{PREVENTING CHRONIC DISEASE}

(continued)

Table 2. Changes in Food Security at 6-Month Assessment Among Participants ( $\mathrm{N}=192)$ in a Food Bank-Based Diabetes Prevention Intervention in Alameda County, California, 2017-2019

\begin{tabular}{|c|c|c|c|c|}
\hline Characteristic & No. of Respondents & Baseline, No. (\%) & 6-Month Assessment, No. (\%) & $P$ Value ${ }^{b}$ \\
\hline \multicolumn{5}{|c|}{ Amount of your household's food supply from food pantries or food giveaways, among those reporting obtaining food from such sources } \\
\hline$<1$ Week's worth & \multirow[t]{3}{*}{155} & $40(25.8)$ & $43(27.7)$ & \multirow[t]{3}{*}{.13} \\
\hline 1 or 2 Weeks' worth & & $97(62.6)$ & $72(46.5)$ & \\
\hline$>2$ Weeks' worth & & $18(11.6)$ & $40(25.8)$ & \\
\hline \multicolumn{5}{|c|}{ Visited food pantry in the last 4 weeks, among those who reported visiting food pantry $\geq 1$ time } \\
\hline Only once - just today & \multirow[t]{2}{*}{169} & $63(37.3)$ & $74(43.8)$ & \multirow[t]{2}{*}{.003} \\
\hline$\geq 2$ Times & & $106(62.7)$ & $95(56.2)$ & \\
\hline
\end{tabular}

Abbreviation: IQR, interquartile range; NA, not applicable.

${ }^{a}$ All values are number (percentage) unless otherwise noted. Food bank staff members administered surveys to food pantry clients aged $\geq 18$ at 12 sites. Includes only participants who completed both the baseline survey and the midpoint survey.

${ }^{\mathrm{b}} P$ value determined by Pearson $x^{2}$ test for categorical indicators and paired $t$ test for continuous indicators.

' USDA Economic Research Service's 6-item screener (18) was used to assess food security score and food security status of participant households. The score was determined by summing individual affirmative answers to the 6 -item assessment. Score is scaled from 0 to 6 , with higher scores indicating low or very low food security. Food security status was categorized as very low (5 or 6); low (2-4); and high or marginal (0 or 1).

${ }^{\mathrm{d}}$ The difference in mean food security score between baseline and 6-month assessment was -0.5 (SD, 1.5). 
Table 3. Changes in Health Outcomes at 6-Month Assessment Among Participants ( $\mathrm{N}=192)$ in a Food Bank-Based Diabetes Prevention Intervention in Alameda County, California, 2017-2019

\begin{tabular}{|c|c|c|c|c|c|}
\hline Characteristic & $\begin{array}{c}\text { No. of } \\
\text { Respondents }\end{array}$ & Baseline & 6-Month Assessment & $\begin{array}{l}\text { Difference, Median } \\
\text { (IQR) }\end{array}$ & $P$ Value $^{\mathrm{b}}$ \\
\hline \multicolumn{6}{|l|}{ General health } \\
\hline $\begin{array}{l}\text { Positive (excellent, very good, or } \\
\text { good) }\end{array}$ & \multirow[t]{2}{*}{188} & $49(26.1 \%)$ & 75 (39.9\%) & \multirow[t]{2}{*}{$-^{\mathrm{c}}$} & \multirow[t]{2}{*}{$<.001$} \\
\hline Negative (fair or poor) & & $139(73.9 \%)$ & $113(60.1 \%)$ & & \\
\hline \multicolumn{6}{|l|}{ Physical activity } \\
\hline $\begin{array}{l}\text { Participate in regular activity once } \\
\text { per week }\end{array}$ & 192 & $120(62.5 \%)$ & $155(80.7 \%)$ & $-^{\mathrm{c}}$ & $<.001$ \\
\hline $\begin{array}{l}\text { Minutes of physical activity in an } \\
\text { average week, mean (median [IQR]) }\end{array}$ & 192 & $95.6(60.0[6.5$ to 145.0$])$ & $\begin{array}{l}145.1(120.0[55.0 \text { to } \\
210.0])\end{array}$ & $\begin{array}{c}+49.4(30.0[-2.5 \text { to } \\
115.0])\end{array}$ & $<.001$ \\
\hline Score of $\geq 3$ on $\mathrm{PHQ}-2^{\mathrm{d}}$ & 192 & $48(25.0 \%)$ & 29 (15.1\%) & $-^{c}$ & $<.001$ \\
\hline \multicolumn{6}{|c|}{ Body mass index, mean (median [IQR]), $\mathrm{kg} / \mathrm{m}^{2}$} \\
\hline All & 184 & 32.4 (32.0 [28.3 to 35.2$])$ & 32.4 (32.0 [28.3 to 35.0]) & $0(0[-0.9$ to 1.0$])$ & .90 \\
\hline Female & 167 & 32.6 (32.1 [28.3 to 35.2$])$ & $32.6(32.1[28.9$ to 35.4$])$ & $0(0[-1.0$ to 1.0$])$ & .90 \\
\hline Male & 17 & $30.6(29.0[28.0$ to 32.6$])$ & $30.6(29.9$ [27.5 to 31.9]) & $0(0[-0.8$ to 0.2$])$ & .98 \\
\hline
\end{tabular}

Abbreviations: IQR, interquartile range; PHQ-2, Patient Health Questionnaire-2.

${ }^{a}$ Food bank staff members administered surveys to food pantry clients aged $\geq 18$ at 12 sites. Includes only participants with no missing values.

${ }^{\mathrm{b}} P$ value determined by Pearson $x^{2}$ test for categorical indicators and paired $t$ test for continuous indicators.

${ }^{c}$ Not calculated.

${ }^{d}$ The PHQ-2 inquires about the frequency of depressed mood in the previous 2 weeks, with a score ranging from 0 to 6 ; if the score is $\geq 3$, a major depressive condition is likely (21). 
Table 4. Changes in Diet-Related Outcomes at 6-Month Assessment Among Participants $(\mathrm{N}=192)$ in a Food Bank-Based Diabetes Prevention Intervention in Alameda County, California, 2017-2019

\begin{tabular}{|c|c|c|c|c|c|}
\hline Outcome & No. of Respondents & Baseline & 6-Month Assessment & Difference & $P$ Value $^{\mathrm{b}}$ \\
\hline \multicolumn{6}{|l|}{ Dietary intake $^{c}$} \\
\hline Any sweetened drinks & 192 & $0.60(0.29$ [0.29 to 1.00$])$ & 0.41 (0.29 [0 to 0.29]) & $-0.19(0[-.042$ to 0$])$ & .002 \\
\hline $100 \%$ pure fruit juice & 192 & 0.260 .29 (0 to 0.29$])$ & 0.28 (0.29 [0 to 0.29]) & $+0.02(0[-0.15$ to 0$])$ & .56 \\
\hline Water & 192 & 2.45 (3.00 [2.00 to 3.00$])$ & 2.57 (3.00 [2.00 to 3.00]) & $+0.12(0[0$ to 0$])$ & .07 \\
\hline Fruit & 192 & 0.89 (1.00 [0.29 to 1.00]) & $0.99(1.00$ [0.29 to 1.00$])$ & $+0.10(0[-0.15$ to 0.71$])$ & .14 \\
\hline Green salad & 192 & $0.43(0.29$ [0.29 to 0.29$])$ & $0.52(0.29[0.29$ to 0.71$])$ & $+0.09(0[0$ to 0.29$])$ & .003 \\
\hline Fried potatoes & 191 & $0.17(0.29$ [0 to 0.29$])$ & $0.14(0$ [0 to 0.29]) & $-0.03(0[-0.29$ to 0$])$ & .02 \\
\hline Other nonfried potatoes & 191 & 0.24 (0.29 [0 to 0.29]) & 0.25 (0.29 [0 to 0.29]) & $+0.01(0[0$ to 0$])$ & .74 \\
\hline Nonfried vegetables & 192 & $0.48(0.29[0.29$ to 0.71$])$ & $0.56(0.29[0.29$ to 0.71$])$ & $+0.08(0[0$ to 0.29$])$ & .03 \\
\hline Cooked beans & 192 & $0.54(0.29$ [0.29 to 1.00$])$ & $0.62(0.29[0.29$ to 1.00$])$ & $+0.08(0[0$ to 0.29$])$ & .03 \\
\hline Pizza & 192 & 0.10 (0 [0 to 0.29$])$ & 0.12 (0 [0 to 0.29]) & $+0.02(0[0$ to 0$])$ & .21 \\
\hline Whole-grain bread & 191 & $0.45(0.29$ [0.29 to 0.71$])$ & $0.52(0.29[0.29$ to 1.00$])$ & $+0.07(0[0$ to 0.29$])$ & .08 \\
\hline Cooked whole grains & 192 & 0.35 (0.29 [0 to 0.29]) & $0.48(0.29[0.29$ to 0.71$])$ & $+0.13(0[0$ to 0.29$])$ & $<.001$ \\
\hline Candy/chocolate & 192 & 0.35 (0.29 [0 to 0.29$])$ & $0.23(0.29$ [0 to 0.29$])$ & $-0.12(0[-0.29$ to 0$])$ & $<.001$ \\
\hline Frozen dessert & 192 & 0.13 (0 [0 to 0.29]) & 0.16 (0 [0 to 0.29]) & $+0.03(0[0$ to 0$])$ & .18 \\
\hline $\begin{array}{l}\text { Cookies, cakes, other sugary } \\
\text { dessert foods }\end{array}$ & 192 & $0.32(0.29$ [0 to 0.29$])$ & $0.23(0.29$ [0 to 0.29$])$ & $-0.09(0[-0.29$ to 0$])$ & .002 \\
\hline Sugary cereals & 191 & $0.12(0$ [0 to 0.29$])$ & 0.11 (0 [0 to 0.29]) & $0(0[0$ to 0$])$ & .84 \\
\hline Nonsugary cereals & 192 & $0.20(0.15$ [0 to 0.29$])$ & 0.21 (0.29 [0 to 0.29]) & +0.01 (0 [0 to 0]) & .57 \\
\hline Whole-grain foods & 191 & 0.99 (0.87 [0.58 to 1.29$])$ & $1.20(1.00$ [0.58 to 1.58$])$ & $\begin{array}{c}+0.21(0.29[-0.29 \text { to } \\
0.71])\end{array}$ & .001 \\
\hline Fruits and vegetables & 191 & 2.83 (2.58 [1.87 to 3.87]) & $3.20(2.87[2.16$ to 4.08$])$ & $\begin{array}{c}+0.37(-0.42[-0.58 \text { to } \\
1.13])\end{array}$ & $<.001$ \\
\hline \multicolumn{6}{|c|}{ Confident in ability to eat fruits and vegetables every day, no. (\%) } \\
\hline Agree & \multirow[t]{3}{*}{188} & $162(86.2)$ & $177(94.2)$ & \multirow[t]{3}{*}{ NA } & \multirow[t]{3}{*}{.09} \\
\hline Neither agree nor disagree & & $7(3.7)$ & $2(1.1)$ & & \\
\hline Disagree & & $19(10.1)$ & $9(4.8)$ & & \\
\hline
\end{tabular}

Abbreviation: IQR, interquartile range; NA, not applicable.

${ }^{a}$ All values are mean [median (IQR)] daily intake frequency unless otherwise noted. Food bank staff members administered surveys to food pantry clients aged $\geq 18$ at 12 sites. Includes only participants with no missing values. Percentages may not sum to 100 due to rounding.

${ }^{\mathrm{b}} P$ value determined by paired $t$ test for dietary recall and Fisher exact test for confidence.

${ }^{\mathrm{c}}$ Questions adapted from the FRESH Foods Survey (19). 
Table 5. Changes in Main Outcomes at 6-Month Assessment for Highly Engaged Participants $(n=95)$ and Less Engaged Participants ( $n=94)$ in a Food Bank-Based Diabetes Prevention Intervention in Alameda County, California, 2017-2019 ${ }^{\text {a }}$

\begin{tabular}{|c|c|c|c|c|c|}
\hline Outcome & $\begin{array}{c}\text { No. of } \\
\text { Respondents }\end{array}$ & Baseline & 6-Month Assessment & Difference & $P$ Value $^{\mathrm{b}}$ \\
\hline \multicolumn{6}{|c|}{ Engagement, no (\%) } \\
\hline Highly engaged & \multirow[t]{2}{*}{189} & NA & $94(49.7 \%)$ & NA & NA \\
\hline Less engaged & & NA & $95(50.3 \%)$ & NA & NA \\
\hline \multicolumn{6}{|c|}{ Food security score ${ }^{c}$} \\
\hline Highly engaged & 95 & 2.47 (2.0 [1.00 to 4.00$])$ & $2.03(2.0[1.0$ to 3.0$])$ & $-0.44(0[-1.0$ to 1.0$])$ & .005 \\
\hline Less engaged & 94 & 3.14 (3.0 [2.00 to 5.00]) & 2.65 (2.0 [1.0 to 4.0$])$ & $-0.49(0[-1.0$ to 0$])$ & .003 \\
\hline \multicolumn{6}{|c|}{ Fruits and vegetables score ${ }^{d}$} \\
\hline Highly engaged & 95 & 2.95 (2.58 [1.87 to 3.87]) & 3.31 (3.15 [2.16 to 4.16$])$ & $+0.36(0.42[-0.71$ to 1.13$])$ & .02 \\
\hline Less engaged & 94 & 2.72 (2.52 [1.87 to 3.71]) & $3.10(2.87$ [2.16 to 3.87$])$ & $+0.38(0.29[-0.42$ to 1.13$])$ & .01 \\
\hline \multicolumn{6}{|c|}{ Whole-grain foods score ${ }^{d}$} \\
\hline Highly engaged & 95 & $1.02(0.87$ [0.29 to 1.58$])$ & $1.28(1.00[0.87$ to 1.58$])$ & $+0.26(0.29[-0.29$ to 0.71$])$ & .10 \\
\hline Less engaged & 94 & 0.97 (0.87 [0.58 to 1.29$])$ & $1.10(0.87[0.58$ to 1.58$])$ & $+0.13(0[-0.29$ to 0.58$])$ & .01 \\
\hline \multicolumn{6}{|c|}{ Minutes of physical activity in an average week } \\
\hline Highly engaged & 95 & $106.8(60.0[7.0$ to 150.0$])$ & 151.5 (120.0 [60.0 to 210.0]) & +44.7 (30.0 [0 to 120.0]) & .02 \\
\hline Less engaged & 94 & $84.5(60.0$ [0 to 140.0$])$ & 138.0 (105.0 [50.0 to 200.0]) & $+53.5(30.0[-3.0$ to 100.0$])$ & $<.001$ \\
\hline
\end{tabular}

Abbreviations: IQR, interquartile range; NA, not applicable.

${ }^{a}$ Dietary values are mean [median (IQR)] daily intake frequency unless otherwise noted. Food bank staff members administered surveys to food pantry clients aged

$\geq 18$ at 12 sites. Highly engaged meant picking up $\geq 70 \%$ of program food packages. Less engaged meant picking up $<70 \%$ of program food packages.

${ }^{\mathrm{b}} P$ value determined by paired $t$ test.

' USDA Economic Research Service's 6-item screener (18) was used to assess food security score and food security status of participant households. The score was determined by summing individual affirmative answers to the 6 -item assessment. Score is scaled from 0 to 6 , with higher scores indicating low or very low food security. Food security status was categorized as very low (5 or 6); low (2-4); and high or marginal (0 or 1).

${ }^{\mathrm{d}}$ Questions adapted from the FRESH Foods Survey (19).

The opinions expressed by authors contributing to this journal do not necessarily reflect the opinions of the U.S. Department of Health and Human Services, the Public Health Service, the Centers for Disease Control and Prevention, or the authors' affiliated institutions. 